\title{
Comment on "The pros and cons of continuous glucose monitoring for patients with type 1 diabetes on multiple daily injections of insulin". Authors' reply
}

\author{
Michela Petrizzo $\mathbb{1}^{1} \cdot$ Maria Ida Maiorino $\mathbb{1}^{1} \cdot$ Katherine Esposito $\mathbb{(}^{1}$
}

Received: 3 January 2018 / Accepted: 9 January 2018 / Published online: 5 February 2018

(c) Springer Science+Business Media, LLC, part of Springer Nature 2018

We are grateful to Dr. Frontino and colleagues for their comments [1] and interest in our work [2]. We acknowledge that type 1 diabetic patients treated with multiple daily injections (MDI) of insulin using continuous glucose monitoring (CGM) may benefit from the use of glucose rate of change (ROC) arrows to make insulin dose adjustments. ROC arrows indicate the direction and velocity of changing glucose, reflecting a combination of recent glucose readings. However, at least three glycemic measurements in the last $15 \mathrm{~min}$ are required to describe the glycemic trend. In order to make safe therapeutic decisions, the information on the velocity of changing glucose should be integrated with that coming from the trend graph and glycemic measurements by self-blood glucose monitoring.

It remains to be clarified whether non-adjunctive use of CGM may be considered a valid tool to make treatment decisions. As Frontino pointed out, the forthcoming availability of more accurate sensors, with mean absolute relative difference (MARD) below 10\%, will provide an important opportunity to monitor glucose levels and adjust therapy with CGM. In the REPLACE-BG trial [3], which randomized 226 type 1 diabetic adults to CGM-only or to CGM plus self blood glucose monitoring (SBGM), mean time in euglycemia (glucose values between $70-180 \mathrm{mg} / \mathrm{dL}$ ) was similar in both groups. However, patients in the CGM-only group needed to perform at least 2.8 SBGM tests per day (mainly to calibrate the sensor), as compared with 5.4 tests of patients in CGM plus SBGM group. Moreover, confirmatory capillary glucose measurements are still required to make therapy adjustments when glucose alerts and

Maria Ida Maiorino

mariaida.maiorino@unicampania.it

1 Diabetes Unit, University of Campania "Luigi Vanvitelli", Naples, Italy readings do not match symptoms or expectations, or in the concomitant assumption of interfering substances, including paracetamol and acetaminophen (www.dexcom.com/enGB). At present, among CGM system, only the Dexcom G5 has been approved for non-adjunctive use in Europe. The flash glucose monitoring (FGM) system, which does not require calibration, offers an alternative glucose monitoring strategy that simultaneously analyzes glucose profile while sparing patients the inconvenience of capillary glucose testing for therapy adjustment or CGM calibration.

\section{Compliance with ethical standards}

Conflict of interest The authors declare that they have no conflict of interest.

\section{References}

1. G. Frontino, V. Favalli, C. Bonura, Comment on "The pros and cons of continuous glucose monitoring for patients with type 1 diabetes on multiple daily injections of insulin". Endocrine 59, 230 (2018). https://doi.org/10.1007/s12020-017-1358-6

2. M.I. Maiorino, M. Petrizzo, G. Bellastella, K. Esposito, Continuous glucose monitoring for patients with type 1 diabetes on multiple daily injections of insulin: pros and cons. Endocrine 59, 62-65 (2018)

3. G. Aleppo, K.J. Ruedy, T.D. Riddlesworth, D.F. Kruger, A.L. Peters, I. Hirsch, R.M. Bergenstal, E. Toschi, A.J. Ahmann, V.N. Shah, M.R. Rickels, B.W. Bode, A. Philis-Tsimikas, R. Pop-Busui, H. Rodriguez, E. Eyth, A. Bhargava, C. Kollman, R.W. Beck, REPLACE-BG Study Group. REPLACE-BG: a randomized trial comparing continuous glucose monitoring with and without routine blood glucose monitoring in adults with well-controlled type 1 diabetes. Diabetes Care 40, 538-545 (2017) 